\title{
Static and Dynamic Characteristics of the Chain Drive System of a Heavy Duty Apron Feeder
}

\author{
Junzhou Huo, Shiqiang Yu*, Jing Yang and Tao Li
}

School of Mechanical Engineering, Dalian University of Technology, Dalian, 116023, China

\begin{abstract}
Mechanical models of a chain drive system are proposed and applied to the theoretical analysis of chain drive system of a certain type of heavy duty apron feeder in mobile crushing station, including a five-bar model discussing the speed fluctuation problems of the chain drive system, an elastic collision model probing the effects of impulsive loads and a model of meshing area revealing the stress of chain links. Theoretical analysis indicates that the teeth number and sprocket pitch have the most influential effect on the vibration in the conveying direction; external impulsive loads are caused a significant increment of chain force, especially when loads caused by large materials; the initial pressure angle affects the roller chain stress conditions immensely. Then, multi-body dynamics models are established for the verification of theoretical results and dynamic simulation. Simulation results are in good agreement with the theoretical results and illustrate that impulsive loads affect chain tension significantly.
\end{abstract}

Keywords: Apron feeder, chain drive system, impulsive loads, meshing area, multi-body dynamics simulation.

\section{INTRODUCTION}

The apron feeder, an essential part of mobile crushing station, typically adopts chain drive system to offer transmission. As an executive component, the chain drive system is prone to encounter fatigue and vibration damage [1].

In recent years, scholars have conducted a wide range of studies on chain drive and made progress in many fields. In [2], the empirical formula of tight-side stress is proposed through a series of experiments. In [3], taking the elastic deformation and dead load of chain roller into account, the mechanical model is built on the basis of the standard tooth profile, and the dead load of tension distribution curve is calculated through Newton-Raphson method. In [4], the multi-body dynamics models of chain drive in large commercial diesel engine are established for analysis and prove that the model with a real tooth profile proves superior to the one with a circular profile. The impulsive load calculation formula for chain drive system is derived in [5], and indicates that the impulsive force between rollers and sprocket tooth is a periodic pulse force which is prone to cause the fatigue failure of rollers. In [6], the paper regards the roller chain as a rigid polygon and reveals some certain reasons that cause the locking phenomenon.

In summary, the existing references comprehensively involve the analyses of dynamics, the load distribution the meshing impact, the polygonal action and the method of reducing the vibration. However, few researchers

*Address correspondence to this author at the School of Mechanical Engineering, Dalian University of Technology, Dalian, 116023, China; Tel: +86 15998568017; Fax: +86 41184707435 ;

E-mail: shiqiang.yu@hotmail.com specifically explain the relationship between design parameters and the speed fluctuation of roller chain, and there are scarce analyses which are carried out in the case of low speed and heavy intermittent external impulsive load. Therefore, this paper, concentrating on the typical working condition of mobile crushing station, conducts an array of theoretical analyses and contrasts analytical results with simulation ones. These works strive to provide support in the design of chain drive system in a heavy duty apron feeder of mobile crushing station.

\section{THE THEORETICAL ANALYSIS}

An apron feeder bears huge loads in work conditions, and any speed fluctuation may cause immense impact loads and the damage of roller and sprocket. This section only focuses on the speed fluctuation originating from the polygonal action and through an equivalent model to analyze factors causing speed fluctuation. In this section, the chain drive system as a rigid body system is treated as rigid system.

\subsection{The Analysis of Speed Fluctuation}

An apron feeder bears huge loads in work conditions, and any speed fluctuation may cause immense impact loads and the damage of roller and sprocket. This section only focuses on the speed fluctuation originated from the polygonal action and analyzes factors resulted in speed fluctuation through an equivalent model. In this section, the chain drive system as a rigid body system is treated as a rigid system.

As indicated in Fig. (1), the right polygon represents driving sprocket. The part 2 in this figure represents the tight-side chain, and all of chain links in this part move in the same way. At any time, there is a segment of chain links that is entering the meshing area (i.e. part 1), meanwhile there is another segment of chain links leaving the meshing 
area (i.e. part 3). All the links in a certain part have the similar law of movement, so these chain links are divided into three independent parts.

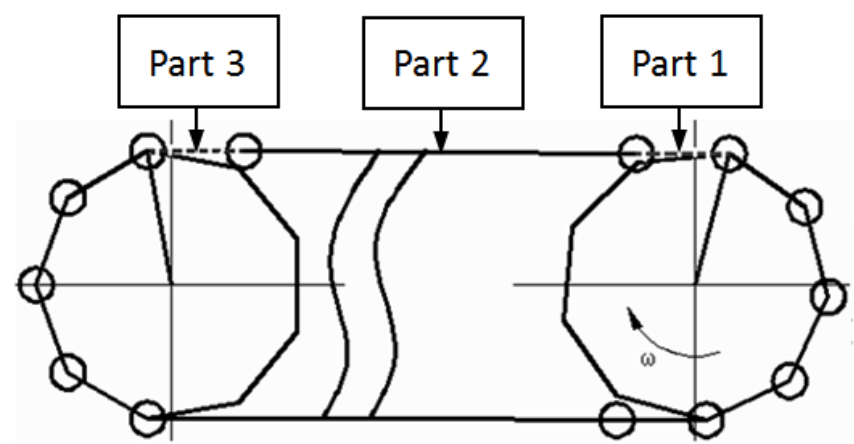

Fig. (1). Model of driving chain system.

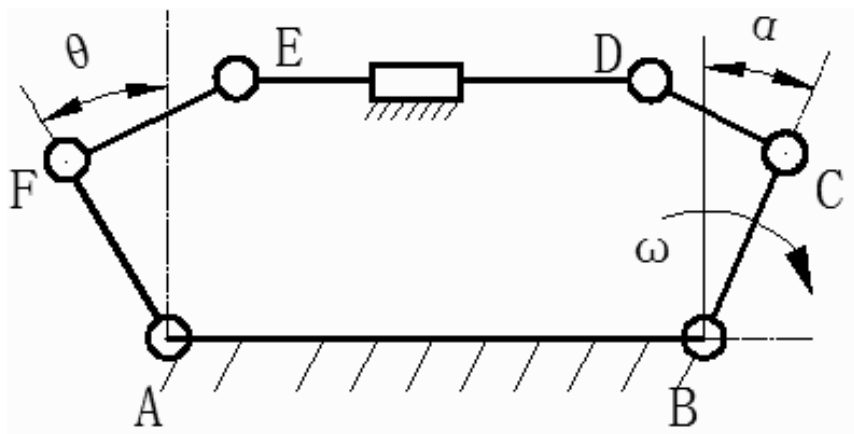

Fig. (2). Five-bar model.

Then, the chain drive system is made equivalent to a fivebar model, as shown in the Fig. (2). Point $\mathrm{F}$ and point $\mathrm{C}$ represent the leftmost roller of part 3 and the rightmost roller of part 1 respectively. As these two rollers are actually located in the meshing area, the distances from the two points to their respective centers of sprocket are equal to the pitch radius of sprocket $(R)$. The connecting rod ED represents the part 2. The connecting rod $\mathrm{BC}$ revolves around the point $\mathrm{B}$. With researching in a certain meshing cycle, the motion characteristics of ED can be recorded entirely. Through resolving the speed vector, the speed of ED $V_{D}$ is given by

$V_{D}=\omega R\left[\cos \alpha+\frac{R(1-\cos \alpha)}{\sqrt{P^{2}-R^{2}(1-\cos \alpha)^{2}}}\right]$.

According to the above derivation, the speed of chain links in tight-side only relates to Rand $\mathrm{P}$ (sprocket pitch). The sprocket pitch $\mathrm{P}=0.2 \mathrm{~m}$, sprocket rotational speed $\omega=0.5 \mathrm{rad} / \mathrm{s}$. As shown in Fig. (3), the 6 curves illustrated the change law of chain links speed, representing the situations of 6 different numbers of teeth $(Z)$ respectively. $Z=9,11,13,15,17,19$ (Different situations are listed for comparison but $Z=13$ in this paper.). According to the results, the number of teeth aggravates the fluctuation, and the speed of chain links in tight-side decreases at the beginning and then rises sharply in a cycle.

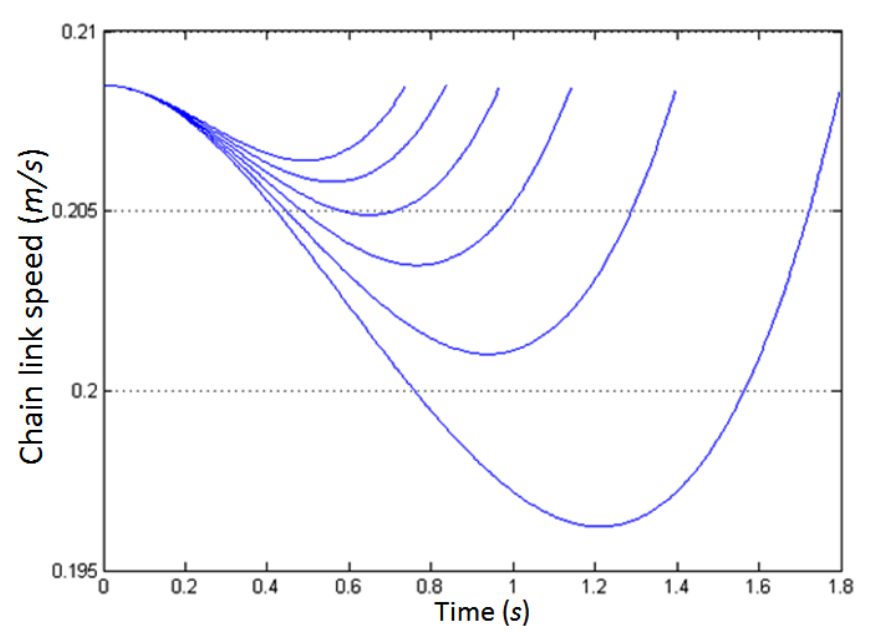

Fig. (3). The chain link speed.

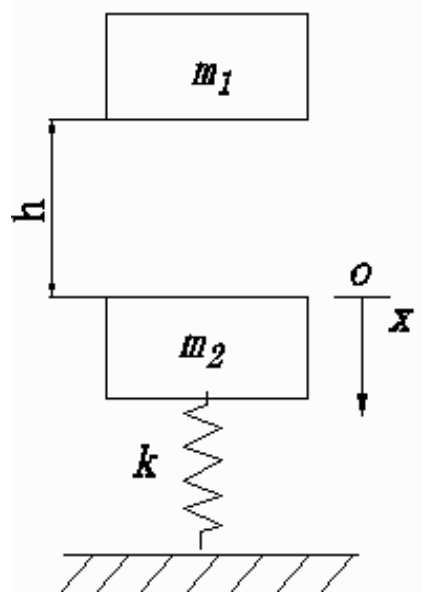

Fig. (4). Collision model.

\subsection{The Effect of Impulsive Loads}

In the actual work process, a roller chain needs to overcome the dead weight of materials, the friction force between apron and materials and the impulsive loads from falling materials. In general, the force on chain drive system can be divided into two parts, the one is a static tension during apron feeder working stably and the other is an additional resistance resulted from impulsive load of materials. This section puts emphasis on the research on the effect of impulsive load.

Although there is compression of rollers, the elongation of chain links is far more than the compression (see [9]). Thus, the compression of roller is neglected in the following model, which only takes the clearance of radius of roller and tooth space and the elongation of chain links into consideration.

The falling materials can be divided into bulk materials and large ones. Typically, the impulsive loads of the former can be calculated by empirical formula. To obtain the impulsive force that stems from falling large materials, in this paper, the apron feeder is made equivalent to an elastic collision model (see Fig. 4). The falling material is mass 
block $m_{1}$, and the equivalent mass of apron feeder is $m_{2}$. The equivalent stiffness of feeder is $k$. The coefficient of friction between roller chain and supporting roller is nearly 0.28 . Through deriving, the tractive resistance on each chain links is given by

$$
\begin{aligned}
F_{f} & =0.28 \times F_{I} \\
& =0.28 \times\left(F_{L}+F_{S}\right) \\
& =0.28\left[\frac{(1+e) m_{1} \sqrt{2 g h m_{2} k}}{m_{1}+m_{2}}+1.225 Q \sqrt{h}\right],
\end{aligned}
$$

where $F_{I}$ is the resultant force on the apron feeder, $F_{L}$ and $F_{S}$ are the impulsive force caused by large and bulk materials, $e$ is the ratio of impulse and $Q$ is the flow rate of bulk materials.

When an apron feeder works stably, the roller chain bears the static tension $F_{k}$ (Process of derivation is omitted in this paper.). According to the design parameters of mobile crushing station, the volume of a shovel of materials is nearly $25 \mathrm{~m}^{3}$, and the maximum diameter of large materials is in the vicinity of $1.5 \mathrm{~m}$. Then, the chain link tension can be calculated (see Table 1).

Table 1. The Calculated Result of Chain Links Tension

\begin{tabular}{|c|c|}
\hline $\begin{array}{c}\text { The Working Condition of Apron } \\
\text { Feeder }\end{array}$ & $\begin{array}{c}\text { Tension on the Chain Link } \\
\text { [KN] }\end{array}$ \\
\hline \hline Stable work condition $\left(F_{k}\right)$ & 430 \\
\hline Impulsive work condition $\left(F_{f}+F_{k}\right)$ & 1020 \\
\hline
\end{tabular}

According to calculated results, the tension when impulsive loads exist is more than twice the results in stable situation. The impulsive loads originate from two parts, large materials $\left(F_{L}=2109 K N\right)$ and bulk materials $\left(F_{S}=189 K N\right)$. Therefore, the impulsive loads should be taken into account in the design process, especially the significant effect of large materials.

\subsection{The Mechanics Model of Meshing Area}

The sprocket teeth and chain links in meshing area, working in harsh stress condition, contribute to transmit torque, so the research on this area is necessary. The radius of roller is slightly less than the radius of tooth space (see [7]). Apart from that, the tension between chain links will stretch the pin link plate and lead to the elongation of chain links. The elongation of chain links is far more than the compression which is neglected in this paper (see [8]).

Each center of roller in the meshing area lies in an arc orbit whose the center coincides with the center of tooth space, and the radius of the arc is $\Delta r=r-d_{1} / 2$ where $d_{1}$ is the diameter of roller and $r$ is the radius of tooth space. Taking two adjacent chain links in meshing area as objects (See Fig. 5), the two circles represent the orbits of centers of two rollers, whose radius is $\Delta r . T_{i-1}$ and $T_{i}$ is the tension on the first $i-1$ and the first $i$ chain link respectively. The engaging force of the first $i$ chain link is $F_{n i}$, and $\theta_{i}$ is the included angle of $F_{n i}$ and $T_{i-1} . \theta_{i}$ and $\theta_{i-1}$ are the pressure angles, and $\Delta \theta_{i}$ is the increment of pressure angle on the first $i$ roller. The elongation is the quotient of the force in the direction of elongation and the stiffness of chain links, and the coefficient of proportionality is $K$. Through the derivation, $T_{i-1}$ is given by

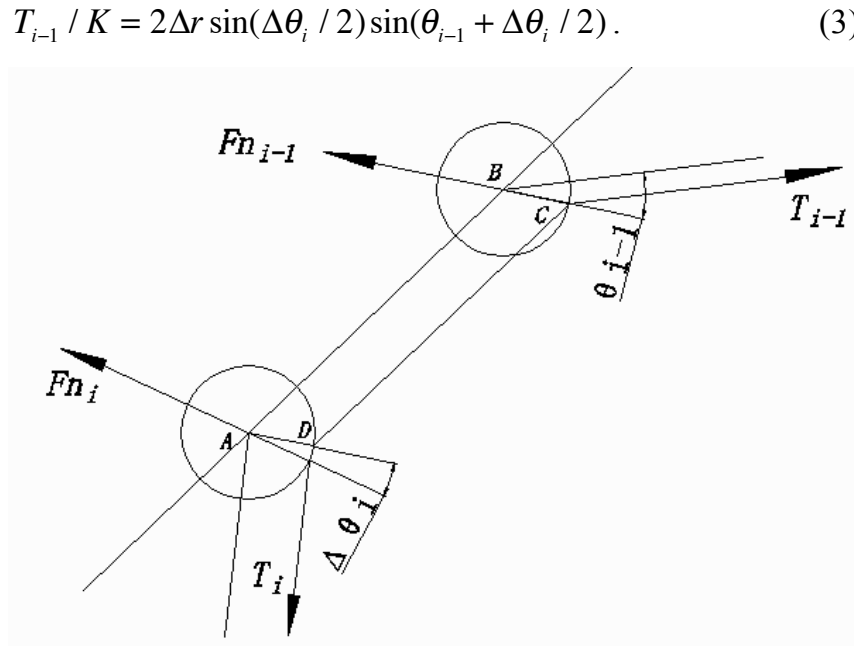

Fig. (5). The force analysis.

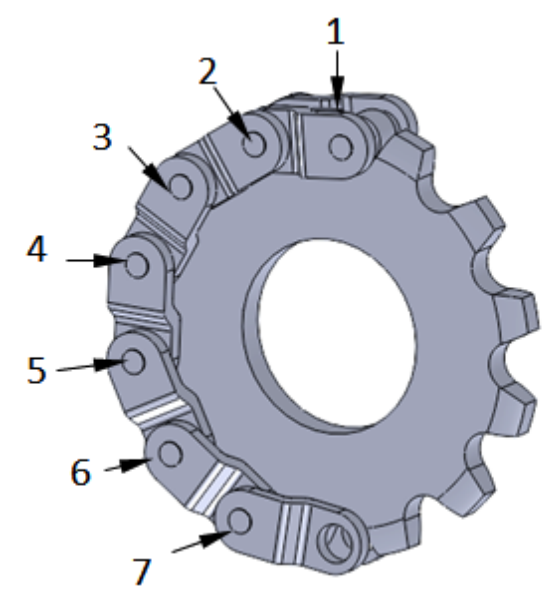

Fig. (6). The serial numbers of rollers.

If $T_{i-1}$ and $\theta_{i-1}$ are known, $\Delta \theta_{i}$ can be calculated by Eq. 3 . Then, other results can be obtained. The pressure angle of the first roller meshed driving sprocket is defined as initial pressure angle, and this section mainly focus on the effect of initial pressure angle.

The position of rollers with different serial number is illustrated in Fig. (6). Correspondingly, pressure angles of different rollers in each situation of initial pressure angle are shown in the Fig. (7). In general, less pressure angle contribute towards the more transmission of torque. According to this line graph, rollers with smaller serial numbers are closer to tight-side chain, and their pressure 


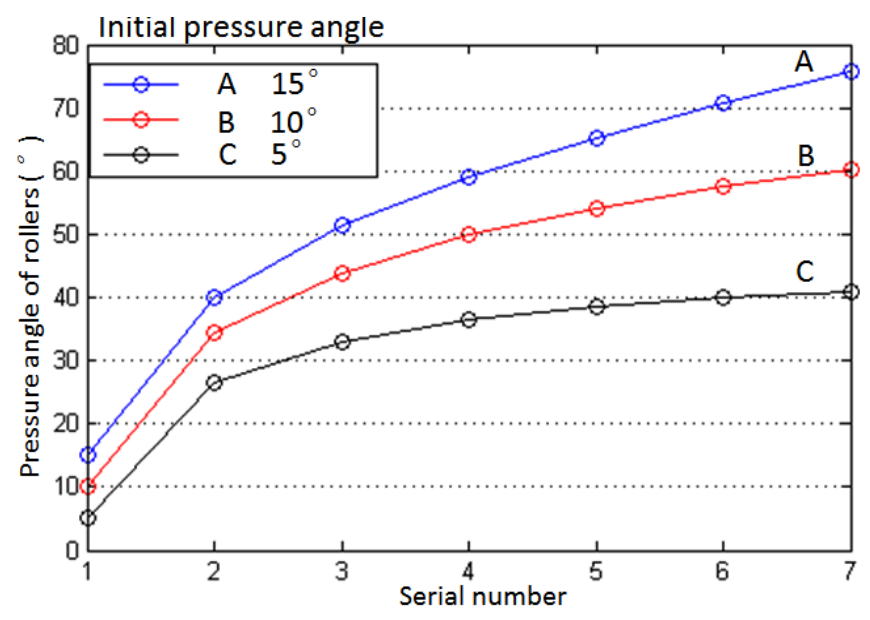

Fig. (7). The effect of initial pressure angle.

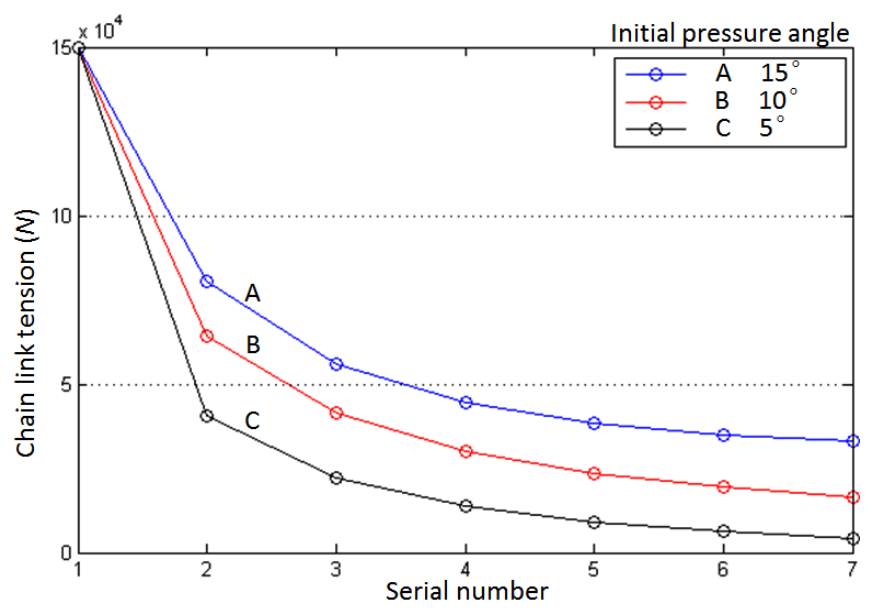

Fig. (8). Chain links forces.

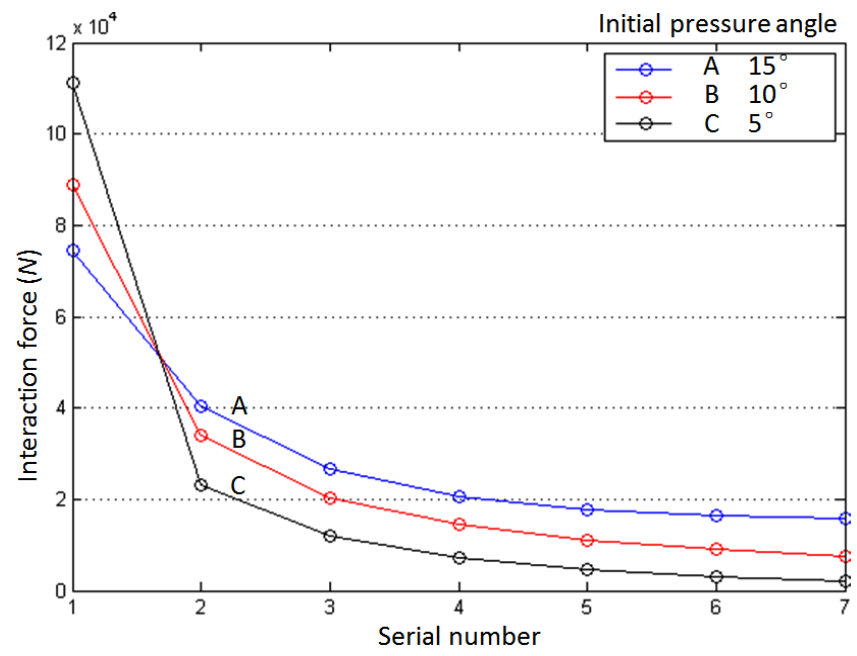

Fig. (9). Interaction forces.

angle are less as well, which means that, in meshing area, those rollers near tight-side chain play more important role in transmitting torque. Also, the tension of chain links and the interaction force between rollers and sprocket are illustrated in Figs. $(\mathbf{8}, 9)$ indicates that larger initial pressure angle exacerbates the stress condition of chain links and sprocket.

\section{VERIFICATION \& DYNAMIC SIMULATION}

For further the research on the dynamic characteristics of chain drive system in apron feeder, this section built threedimensional assembly model of chain drive system for simulation in the multi-body dynamics software RecurDyn, aiming to verify the theoretical derivation and analytical results.

\subsection{Verification of the Speed Fluctuation Formula}

As the five-bar model for researching speed fluctuation in 2.1 is an ideal model based on a series of hypothesis, which may differ from the real situation in some extent, this paper strives to verify the accuracy of theoretical analysis through multi-body dynamics simulation.

The speed of the horizontal chain in five-bar model is associated with the movement of driving sprocket instead of driven sprocket. As a result, it is not necessary to establish a whole assembly model of chain drive system. The parameters of chain drive system model for simulation are the same as the ones mentioned in the above paragraphs.

As shown in Fig. (10), to keep the tension in tight-side chain, the constant force $F_{t}=150 \mathrm{kN}$ is attached in the right side of tight-side chain. Unlike installing supporting roller $\mathrm{s}$ in a real chain drive system, a series of rollers for supporting will aggravate the burden on computing, so cuboids are used to support the tight-side chain rather than the real supporting roller, which actually works as guide rail primarily due to the tight layout of supporting rollers.

After the pre-processing of this model, several factors, including boundary conditions, driving force and other relationship between components, need to be set on the basis of real load and constraint conditions. Being endowed with certain flexibility, adjacent chain links hinge at each other and are restrained other five degrees of freedom. The kinematic pair for rotating is added to the center of driving sprocket. Due to the effect of supporting component, collisions are liable to occur between several rollers and supporting cuboids, both of which are solid model, so the relationship between chain links and supporting components should be defined as 'Solid Contact'.

According to the theoretical analysis, the cycle of speed changes of chain links is equal to the cycle of meshing, so the time span of simulation is set equal to a cycle of meshing (0.966s). During the process of simulation, recording the law of movement of a certain roller could reflect the kinetic characteristic of the whole tight-side chain.

The simulation results and analytical results are illustrated in the same figure (see Fig. 11), from which the curve of theoretical results is relatively smoother than simulation results. According to the process of simulation, the first area that oscillation occurred is caused by the collision contact between roller and sprocket space, such a collision last a period of time before the collision force reducing to a certain threshold. In the second half of meshing cycle, as the certain roller entering into the meshing area is 


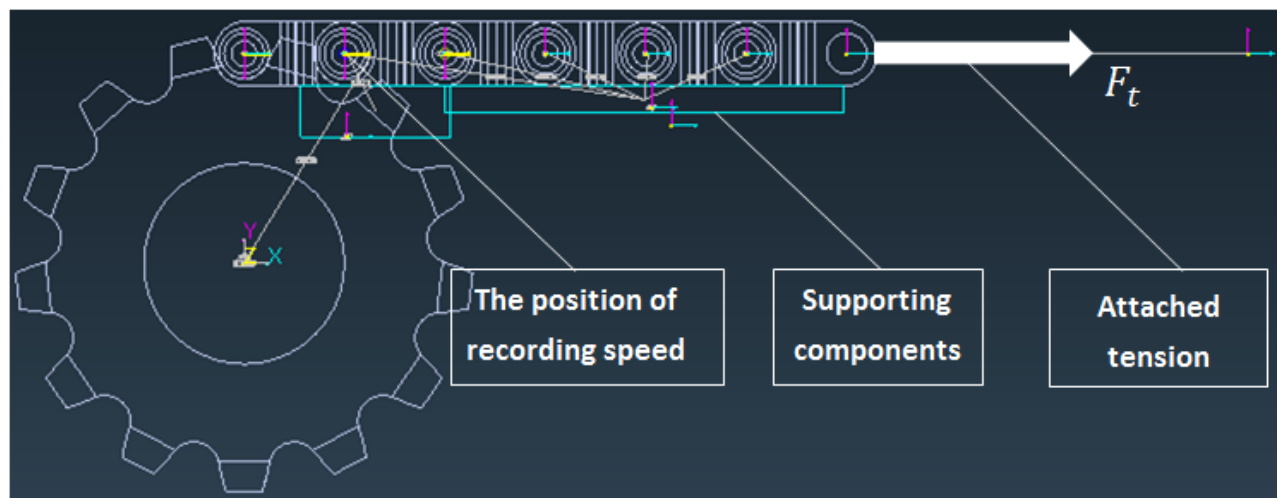

Fig. (10). Model for simulation.

gradually getting rid of the effect of supporting components, it becomes unstable and affects chain links nearby. Then, such a change affects the roller under monitoring, so the oscillation occurred again.

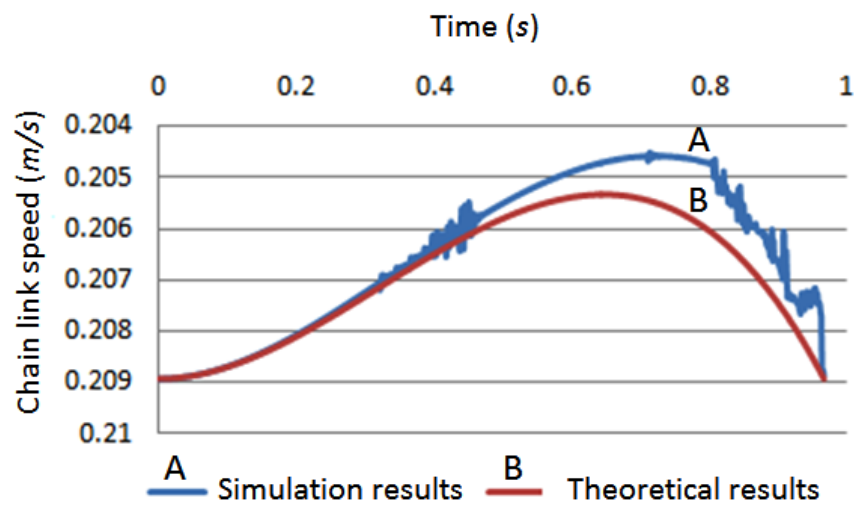

Fig. (11). Chain links speed curves.

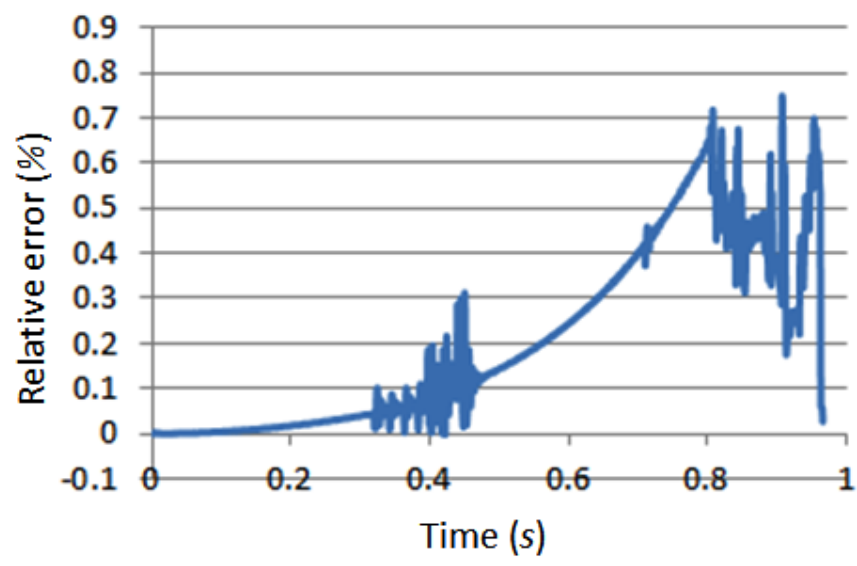

Fig. (12). Relative error curves.

Comparing theoretical results with simulation ones, both of them experience the same trends. In addition, the speeds of the first and the last chain links in two curves are approximately equal. Two of curves peak at almost the adjacent time intervals, the difference may be caused by tooth profile clearance. According to the relative error curve, as shown in Fig. (12), the maximum error is nearly $0.75 \%$, which means that the theoretical analysis based on five-bar model for solving change law of speed fluctuation is feasible and practicable in a large extent.

\subsection{Simulation of Meshing Area}

In this section, to contrast the theoretical results with simulation, the assembly model of meshing area is built in RecurDyn (see Fig. 13).

The model added a tension $F_{t}=150 \mathrm{kN}$ in the first chain link near the tight-side chain and attached a slight tension $F_{s}$ in the last chain link to avoid chain links falling. As the process is a static analysis, the center of sprocket is fixed to the ground.

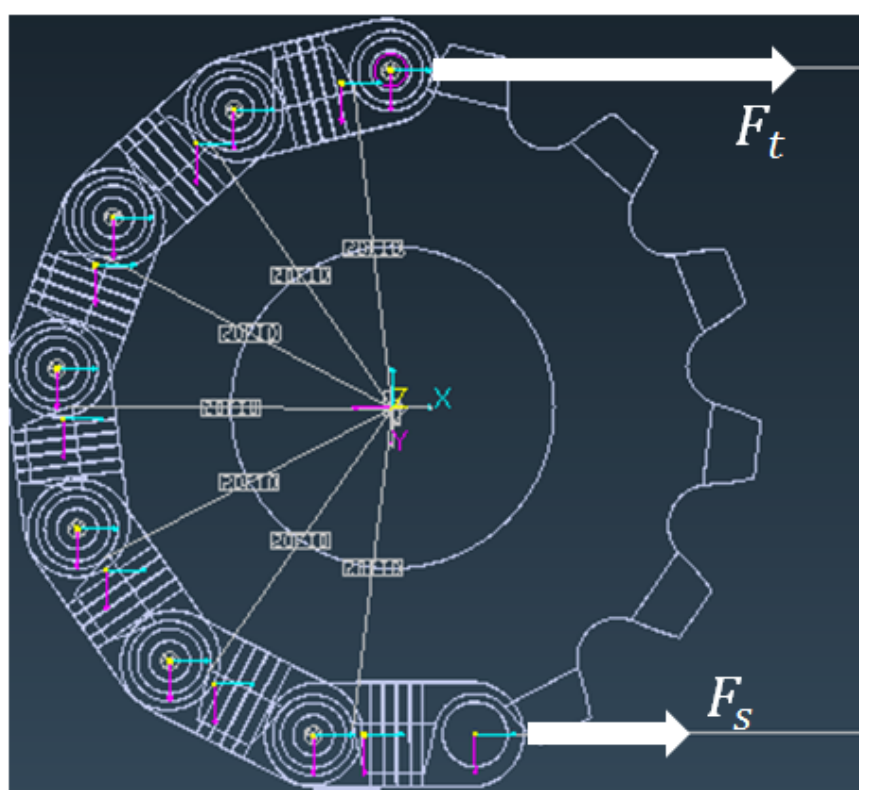

Fig. (13). Assembly model of meshing area.

Comparing with theoretical results, the simulation results of interaction forces of all the rollers are illustrated in the line graph, as shown in Fig. (14). The line of simulation results, overlapping with other lines drawn in some extent, is approximately located between the line that the initial pressure angle is $5^{\circ}$ and the line that the initial pressure angle is $15^{\circ}$. The analysis indicates that the simulation results coincide with the theoretical results in certain extent.

Similarly, comparing with theoretical results of chain link tensions (see Fig. 15), the line of simulation results is approximately located between the line that the initial 
pressure angle is $5^{\circ}$ and the line that the initial pressure angle is $15^{\circ}$.

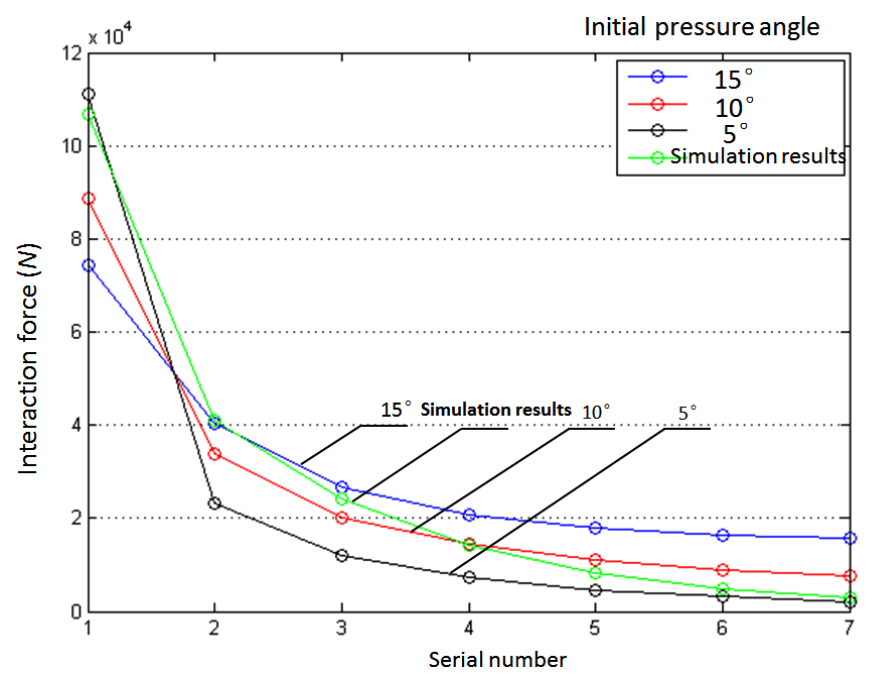

Fig. (14). Comparison of interaction force.

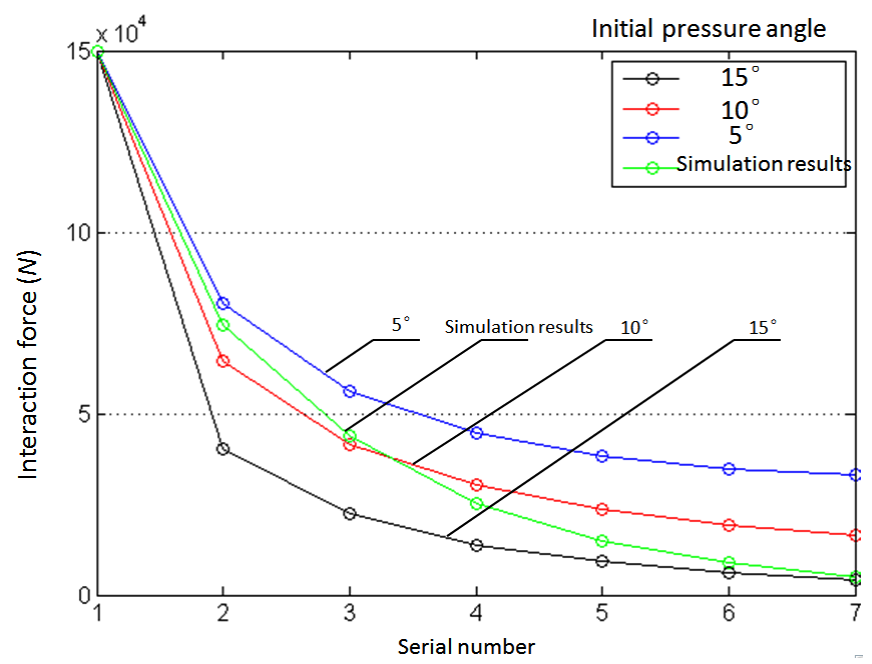

Fig. (15). Comparison of chain links tension.

In summary, the above comparison indicates that the simulation results coincide with the theoretical results in certain extent. So, the theoretical model could reflect the stress condition of meshing area, having some referenced meaning for the design of chain drive system.

\subsection{The Dynamics Simulation}

Through building the physical model of chain drive system, the multi-body simulation software transfers it into a mathematical model to solve and obtain the dynamic response characteristics. As the center distance of chain drive system is too much large (as long as $10 \mathrm{~m}$ in length). Therefore, this paper diminishes the center distance to improve the calculating efficiency. The Fig. (16) shows the assembly model of chain drive system.

After pre-processing, the simplified entity components include 1 supporting board, 2 sprockets, 33 chain links. As the model is larger than previous ones, there are a great number of contact pairs, illustrating as Fig. (17). To solve the tension of chain links, 'Bushing' force unit in RecurDyn is used to link the adjacent chain links.

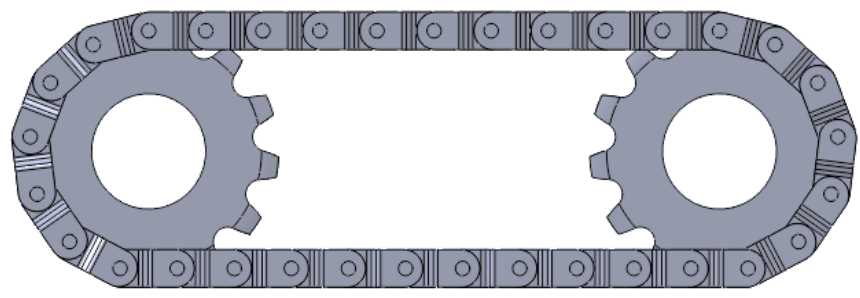

Fig. (16). Assembly model.

If external impulsive loads are neglected in the process of stable working condition, the torque on driving sprocket is approximately invariable. Through calculation, the circle force on single chain link is $1.5 e^{5} N$, which can be transferred into resistance torque $M_{f}=6.62 \times 10^{4} \mathrm{~N} \cdot \mathrm{m}$. This paper takes intermittent impulsive loads in real working condition into account, adding an extra torque is given by

$$
\begin{aligned}
M_{f 1} & =\mu \sum F R \\
& =1.25 \times 10^{5} \mathrm{~N} \cdot \mathrm{m},
\end{aligned}
$$

where $\mu$ is the friction coefficient between supporting components and roller chain, and $\sum F$ is impact force exerted on roller chain vertically. According to statistics recorded in real work process of apron feeder, it typically takes $1 s$ for a shovel of materials to falling from the beginning of contacting to completing the whole process. The transferred load torque is expressed as sine function (see the Fig. 18).

Following simulation results demonstrate the effect that external impulsive load has on driven sprocket rotational speed, chain tension, interaction force between rollers and driving sprocket.

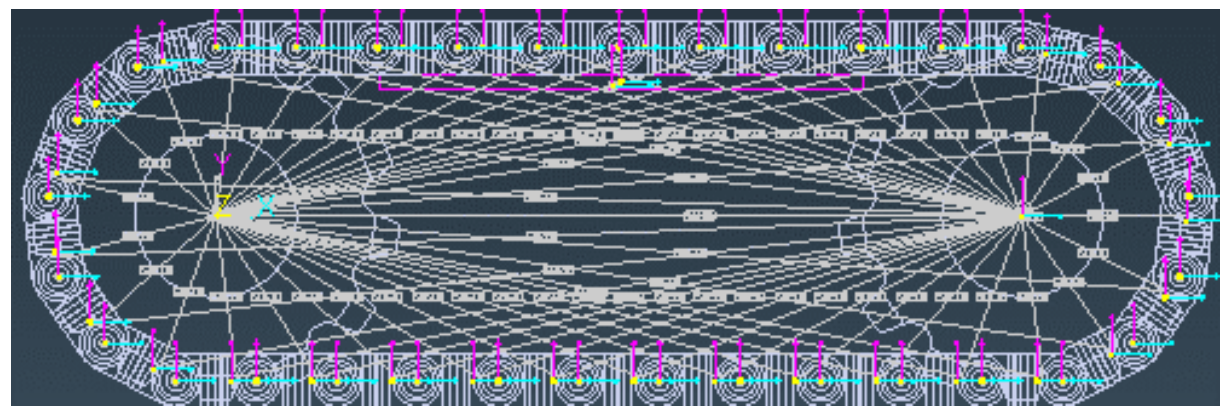

Fig. (17). Contact pairs. 


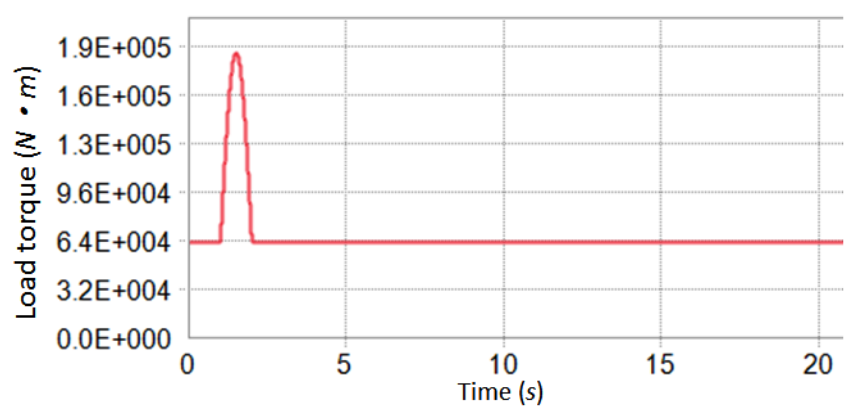

Fig. (18). Load torque on driving sprocket.

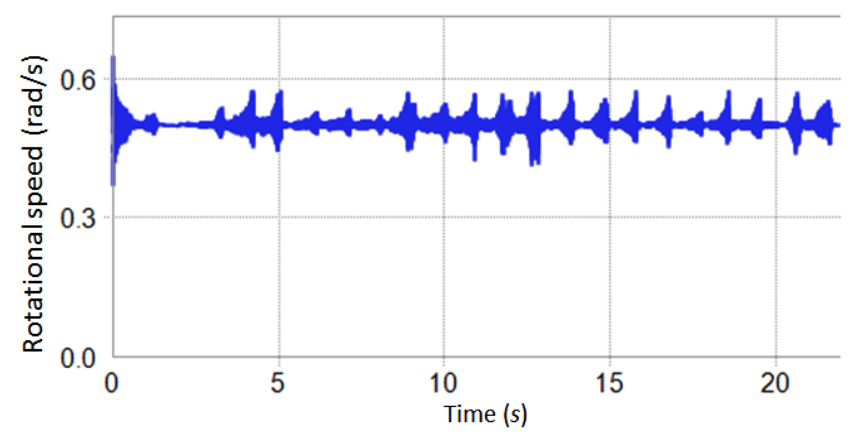

Fig. (19). Rotation speed of the driven sprocket.

According to Fig. (19), the external impulsive load has little effect on driven sprocket speed and the average transmission ratio. So, the intermittent impulsive loads in the work process of apron feeder rarely affect the movement of driven sprocket.

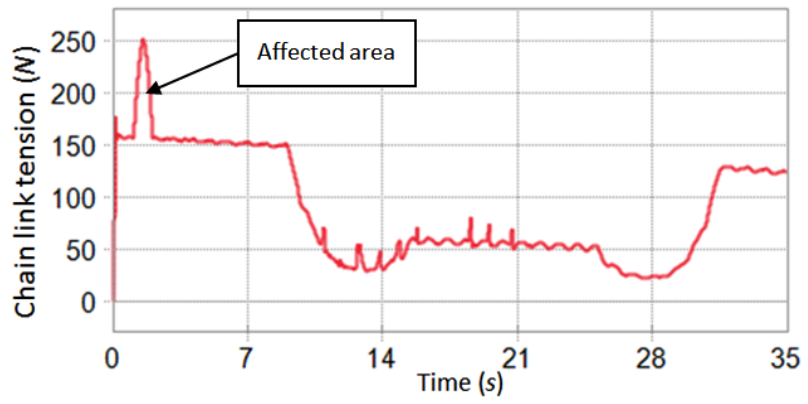

Fig. (20). Tension in tight-side chain.

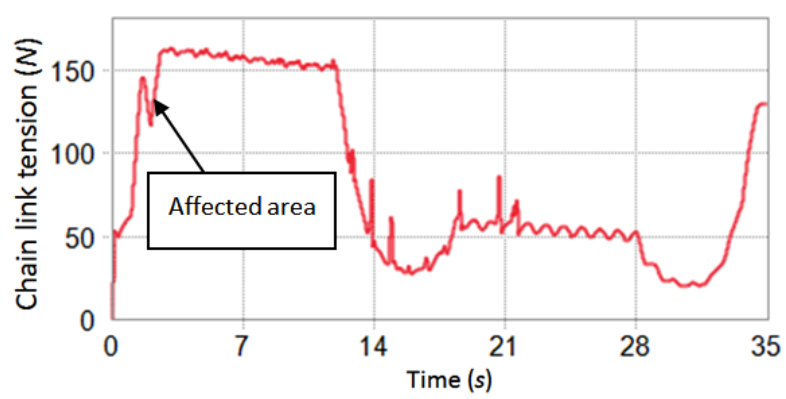

Fig. (21). Tension in meshing area.

For chain link in the tight-side chain (see Fig. 20), its tension rise correspondingly as the impulsive load exert on the apron feeder, increasing from approximately $150 \mathrm{KN}$ to $250 K N$, which indicates that the increment of load torque affects tight-side chain tension significantly. For the chain links in meshing area (see Fig. 21), its tension is affected by the impulsive load as well, but the rise of chain link tension in meshing area is relatively moderate than the sharp increase on tight-side chain links.

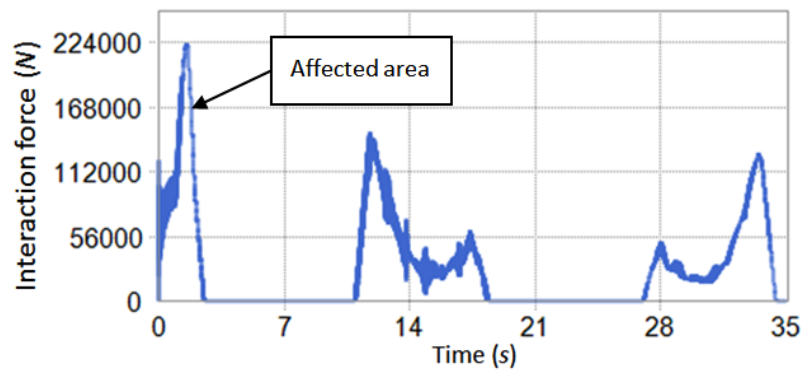

Fig. (22). Forces between roller and driving sprocket.

The change of interaction force between roller and driving sprocket is indicated in Fig. (22). When the impulsive load torque appears, the interaction force increases dramatically, and the interaction force peaks at the same time.

\section{CONCLUSIONS}

(1) The five-bar model is put forward to discuss reasons resulted in the speed fluctuation. The analytical results indicate that the speed change is related to sprocket pitch, pitch radius and the number of teeth; the speed fluctuation of roller chain is significant, which may cause severe vibration.

According to the calculation results in the collision model, large materials generate as several times force as bulk materials do. Comparing with the result calculated in stable working condition, the impulsive loads from a shovel of materials almost double chain tension.

(3) Through the mechanics model of meshing area, this paper calculated chain tension and the interaction force between rollers and sprocket in meshing area. The results reveal that the initial pressure angle have effects on chain links forces and interaction forces.

(4) The speed fluctuation formula derived in this paper and theoretical analysis in meshing area are verified by simulation. Theoretical results are approximately consistent with the simulation results, which indicate that the formula and theoretical mechanics model is feasible in some extent.

(5) According to multi-body simulation results, the dynamic characteristics of chain drive system with external impulsive load are researched. Simulation results indicate that impulsive loads cause relatively moderate effect on the chain tension of meshing area chain links. However, the effect of impulsive load on chain tension in tight-side chain is significant.

\section{CONFLICT OF INTEREST}

The authors confirm that this article content has no conflict of interest. 


\section{ACKNOWLEDGEMENTS}

This work is supported by the National Natural Science Foundation for Young Scholars of China (Grant No.51005033), the Major State Basic Research Development Program of China (973 Program) (Granted No. 2013CB035400), the Liaoning Key Science and Technology Project (Granted No. 2011220031).

\section{REFERENCES}

[1] H. Li, D. Fan, and Y. Bao, "The problems lies in apron feeder and improvement measures", Block-Brick, no. 6, pp. 21-22. 2007.

[2] J.C. Conwell, and G. E. Johnson, "Experimental investigation of link tension and roller-sprocket impact in roller chain drives", Mechanism and Machine Theory, vol. 31, no. 4, pp. 533-536. 1995

[3] I. Troedsson, and L. Vedmar, "A method to determine the static load distribution in a chain drive", Journal of Mechanical Design ASME, vol. 121, no. 9, pp. 402-408, 1999.
[4] S.L. Pedersen, "Model of contact between rollers and sprockets in chain-drive systems", Archive of Applied Mechanics, vol. 74, no. 7, pp. 489-508, 2005.

[5] C. Rong, Y. Wang, and X. Ning, "Analysis of meshing impact on roll chain drive", Mining \& Processing Equipment, no. 7, pp. 4547, 2003.

[6] H. Ding, and G. Ren, "Modeling and simulation of the chainsprocket system with multi grid body method", Mechanics and Engineering, vol. 27, pp. 14-18, 2005.

[7] G. Zhang, X. Xiang and H. Tang, "Field test and numerical calculation of restitution coefficient of rockfall collision", Chinese Journal of Rock Mechanics and Engineering, vol. 30, no. 6, pp. 1266-1269, 2011.

[8] S.L. Pedersen, "Model of contact between rollers and sprockets in chain-drive systems", Multibody system dynamics, vol. 12, no. 3, pp. 285-301.

[9] S.L. Pedersen. A, "Roller chain drive model including contact with guide-bars", Multibody system dynamics, vol. 12, no. 3, pp. 285301.

(C) Huo et al.; Licensee Bentham Open.

This is an open access article licensed under the terms of the Creative Commons Attribution Non-Commercial License (http://creativecommons.org/licenses/by-nc/3.0/) which permits unrestricted, non-commercial use, distribution and reproduction in any medium, provided the work is properly cited. 